\title{
Synthesis of silver nanoparticles with antibacterial activity using the lichen Parmotrema praesorediosum
}

This article was published in the following Dove Press journal:

International Journal of Nanomedicine

19 December 2013

Number of times this article has been viewed

Ropisah Mie ${ }^{1,2}$

Mohd Wahid Samsudin'

Laily B Din'

Azizan Ahmad'

Nazlina Ibrahim ${ }^{3}$

Siti Noor Adnalizawati

Adnan $^{3}$

'School of Chemical Sciences and Food Technology, Faculty of Science and Technology, Universiti Kebangsaan Malaysia, Selangor, ${ }^{2}$ Faculty of Applied Sciences, Universiti Teknologi MARA Negeri Sembilan, Negeri Sembilan, ${ }^{3}$ School of Biosciences and Biotechnology, Faculty of Science and Technology, Universiti Kebangsaan Malaysia, Selangor, Malaysia
Correspondence: Mohd Wahid Samsudin School of Chemical Sciences and Food Technology, Faculty of Sciences and Technology, Universiti Kebangsaan Malaysia, 43300 UKM Bangi,

Selangor, Malaysia

$\mathrm{Tel}+60389215412$

Fax +603 8925I 5410

Email wahid@ukm.my

\begin{abstract}
Development of a green chemistry process for the synthesis of silver nanoparticles has become a focus of interest. This would offer numerous benefits, including ecofriendliness and compatibility for biomedical applications. Here we report the synthesis of silver nanoparticles from the reduction of silver nitrate and an aqueous extract of the lichen Parmotrema praesorediosum as a reductant as well as a stabilizer. The physical appearance of these silver nanoparticles was characterized using ultraviolet-visible spectroscopy, electron microscopy, energy-dispersive spectroscopy, and X-ray diffraction techniques. The results show that silver nanoparticles synthesized using $P$. praesorediosum have an average particle size of $19 \mathrm{~nm}$ with a cubic structure. The antibacterial activity of the synthesized silver nanoparticles was tested against eight micro-organisms using the disk diffusion method. The results reveal that silver nanoparticles synthesized using $P$. praesorediosum have potential antibacterial activity against Gram-negative bacteria.
\end{abstract}

Keywords: silver nanoparticles, lichens, Parmotrema praesorediosum, antibacterial activity

\section{Introduction}

The "green" chemistry approach to synthesizing biocompatible silver nanoparticles (AgNPs) has gained considerable attention in recent years. Plants or natural resources has been found to be a good alternative method for nanoparticle synthesis, since this method does not use any toxic chemicals and does not require the use of high pressure, energy, and temperature. This green chemistry process has numerous benefits, including environmental friendliness, cost-effectiveness, and suitability for pharmaceutical and biomedical applications. Plants and natural resources, such as papaya, ${ }^{1}$ Lippia citriodora, ${ }^{2}$ Helianthus annus, ${ }^{3}$ Camellia sinensis,${ }^{4}$ and Aloe vera,${ }^{5}$ has been used for the synthesis of metal nanoparticles.

Silver nanoparticles have become a focus of interest because they play a significant role in biological systems, living organisms, and medicine. ${ }^{6,7}$ In the present medical industry, silver and AgNPs have been found to be very useful in preventing infection in burns and open wounds. ${ }^{8}$ Silver nanoparticles have also been reported to possess antifungal, ${ }^{9}$ antiviral, ${ }^{10}$ and antiplatelet activity. ${ }^{11}$ They are also beneficial as antimicrobials and therapeutic agents, ${ }^{12,13}$ and the development of AgNPs as an antibacterial agent is under way.

The aim of this study was to synthesize AgNPs using an aqueous extract of the lichen Parmotrema praesorediosum. Lichens are of special interest in synthesizing AgNPs because they are a composite organism consisting of a symbiotic association between a fungus and green algae. ${ }^{14}$ Lichen extracts contain a wide variety of metabolites, such 
as polysaccharide (homo-D-glucan) and phenolic (depside, depsidon, and dibenzofurane) compounds ${ }^{15,16}$ that can potentially act as reducing agents for silver ions. P. praesorediosum presents unique properties in that it has two aliphatic acids, ie, (+)-praesorediosic acid [2-(14'-carboxytetradecyl)-4methyl-5-oxo-2,5-dihydrofuran-3-carboxylic acid] and (+)-protopraesorediosic acid [2-(14'-carboxytetradecyl)-4methylene-5-oxo-2,5-tetrahydrofuran-3-carboxylic acid], which can play a significant role in the synthesis of AgNPs. The synthesis, characterization, and antibacterial activity of AgNPs against eight pathogenic micro-organisms were evaluated in this study.

\section{Materials and methods Materials}

P. praesorediosum was collected from several lowland areas, including Bukit Mahkota Selangor, Malaysia. Silver nitrate $\left(\mathrm{AgNO}_{3}\right)$ was purchased from Merck (Darmstadt, Germany). Mueller-Hinton agar, Mueller-Hinton broth, and nutrient broth were purchased from Oxoid Ltd (Basingstoke, UK) for the antibacterial assays.

\section{Synthesis of AgNPs}

An aqueous extract of $P$. praesorediosum was prepared by mixing $3 \mathrm{~g}$ of a lichen sample with $45 \mathrm{~mL}$ of ultrahigh purity water (Milli-Q, Millipore, Billerica, MA, USA). The mixture was heated for several minutes at $80^{\circ} \mathrm{C}$ to denature the enzymes in the extract. The solution was filtered through Whatman No 1 filter paper (pore size $125 \mathrm{~mm}$ ). The filtrate was further filtered through Whatman No 1 filter paper (pore size $25 \mu \mathrm{m}$ ) to remove plant residues. For synthesis of the AgNPs, about $10 \mathrm{~mL}$ of the aqueous lichen extract was mixed with $30 \mathrm{~mL}$ of a $1 \mathrm{mM} \mathrm{AgNO}_{3}$ solution in an Erlenmeyer flask and allowed to react at room temperature for 24 hours. Use of ultrahigh purity water avoids the presence of chloride ions and prevents precipitation of silver chloride. A dried AgNP powder was obtained by freeze-drying and stored at $4^{\circ} \mathrm{C}$ until further analysis. The AgNPs in the freezedrying bottle were resuspended in ultrahigh purity water for all characterization methods and antibacterial assays.

\section{Characterization of AgNPs}

The reduction of silver ions to AgNPs in the solution was monitored by measuring the ultraviolet-visible spectrum of the solution using a UV 2450 double-beam spectrophotometer (Shimadzu, Tokyo, Japan) operated at a resolution of $2 \mathrm{~nm}$ in the range from $300-600 \mathrm{~nm}$. The physical appearance of the synthesized AgNPs was analyzed by transmission electron microscopy (TEM), energy-dispersive spectroscopy, and X-ray diffractometry. TEM analysis of the AgNPs was performed using a CM12 instrument operated at an accelerating voltage at $80 \mathrm{kV}$ (Philips, Eindhoven, the Netherlands). Samples were prepared by drop-coating on formvar-coated copper TEM grids. The size distribution of the AgNPs was calculated from the TEM images by measuring the diameter of approximately 50 nanoparticles. Further, the presence of elemental silver was confirmed by energy-dispersive spectroscopy and phase identification of the AgNPs was done using X-ray diffractometry.

\section{Evaluation of antibacterial activity of AgNPs}

The antibacterial activity of the synthesized AgNPs was determined using the disk diffusion method. ${ }^{17}$ Eight types of pathogenic bacteria, including four Gram-negative bacteria (Proteus vulgaris, Pseudomonas aeruginosa, Serratia marcescens, Salmonella typhi) and four Gram-positive bacteria (Staphylococcus epidermidis, methicillin-resistant Staphylococcus aureus, Bacillus subtilis, and Streptococcus faecalis) were tested. Pure cultures of the micro-organisms were subcultured on Mueller-Hinton agar. Each strain was swabbed uniformly onto individual agar plates using sterile cotton swabs. Sterile paper disks were placed on the agar plates, and $10 \mu \mathrm{L}$ of $100 \mu \mathrm{g} / \mathrm{mL}$ (w/v) samples were applied to the disks. Gentamicin ( $30 \mu \mathrm{g}$ per disk) was used as the positive control and sterile distilled water as the negative control. All the plates were incubated at $37^{\circ} \mathrm{C}$ for $18-24$ hours. The tests were repeated three times. The zone of inhibition, which appeared as a clear area around the disks, was measured.

\section{Results}

Formation of AgNPs in aqueous extract can be monitored by color change. Figure 1 shows the color changes when the aqueous extract of $P$. praesorediosum was mixed with a $1 \mathrm{mM}$ $\mathrm{AgNO}_{3}$ solution. The mixture was kept at room temperature for 24 hours. The appearance of a yellowish-brown color in the reaction vessel indicated formation of AgNPs. ${ }^{18}$ AgNPs exhibit this yellowish-brown color in aqueous solution due to excitation of surface plasmon resonance in the AgNPs. ${ }^{19}$

Ultraviolet-visible spectroscopy was used to characterize the synthesized AgNPs. As shown in Figure 2, the surface plasmon resonance of the AgNPs was centered at approximately $408 \mathrm{~nm}$, indicating the presence of AgNPs in the solution.

The morphology and size distribution of the synthesized AgNPs were determined by TEM analysis. The TEM image 


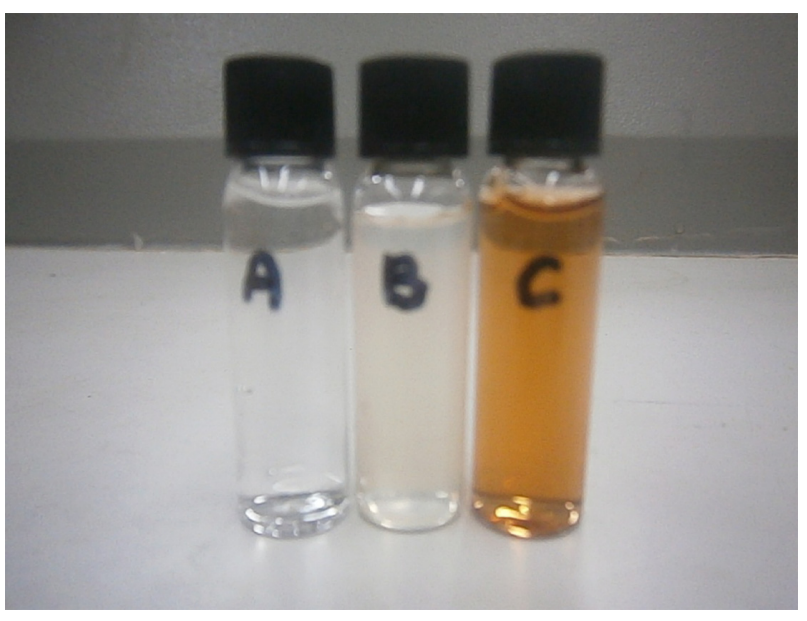

Figure I The I mM $\mathrm{AgNO}_{3}$ solution (A), aqueous extract of Parmotrema praesorediosum (B), and a mixture of $P$. praesorediosum in $1 \mathrm{mM} \mathrm{AgNO}_{3}$ after 24 hours of reaction $(\mathbf{C})$.

Abbreviation: $\mathrm{AgNO}_{3}$, silver nitrate.

in Figure 3 shows that the particles were polydispersed and mostly spherical. The particle size histograms for the AgNPs (shown on the right side of Figure 3) suggest that the particles ranged in size from $5 \mathrm{~nm}$ to $40 \mathrm{~nm}$ with an average diameter of $19 \mathrm{~nm}$.

The synthesized AgNPs were further characterized using $\mathrm{X}$-ray diffractometry (Figure 4$)$. The $\mathrm{X}$-ray diffraction pattern showed four intense peaks $\left(38.2^{\circ}, 44.3^{\circ}, 64.5^{\circ}, 77.5^{\circ}\right)$ in the whole spectrum of $2 \theta$ values ranging from $20^{\circ}$ to $80^{\circ}$, which correspond to the (111), (200), (220), and (311) crystallographic planes of face-centered cubic silver, respectively.
The crystallite domain size was calculated using the Debye-Scherrer formula: $\mathrm{D}=0.94 \lambda / \beta \cos \theta$, where $\mathrm{D}$ is the average crystallite domain size perpendicular to the reflecting planes, $\lambda$ is the wavelength of $\mathrm{Cu}_{\mathrm{k} \alpha}, \beta$ is the full width at half maximum, and $\theta$ is the Bragg diffraction angle. The average crystallite size of the synthesized AgNPs was $15.4 \mathrm{~nm}$, derived from the full width at half maximum of peak corresponding to the (111) plane, which is in a good agreement with the particle size determined by TEM analysis.

Reduction of silver ions to elemental silver by the aqueous extract of $P$. praesorediosum was confirmed by energydispersive spectroscopy (Figure 5). The silver nanocrystallites displayed an optical absorption band peak at approximately $3 \mathrm{KeV}$, which is typical of the absorption of metallic silver nanocrystallites due to surface plasmon resonance. ${ }^{20}$

The antibacterial effects of silver salts have been known since antiquity, ${ }^{21}$ but the use of AgNPs as an antibacterial agent is relatively new. Therefore, the antibacterial activity of the synthesized AgNPs against Gram-negative and Gram-positive bacteria was investigated. At a concentration of $100 \mu \mathrm{g} / \mathrm{mL}$, the AgNPs efficiently inhibited the growth of Gram-negative bacteria. Figure 6 shows the antibacterial activity of AgNPs against S. typhi. The diameters of the inhibition zones for the all tested pathogens are listed in Table 1. Thus, our results show that AgNPs synthesized using an aqueous extract of $P$. praesorediosum have potential antibacterial activity against Gram-negative bacteria.

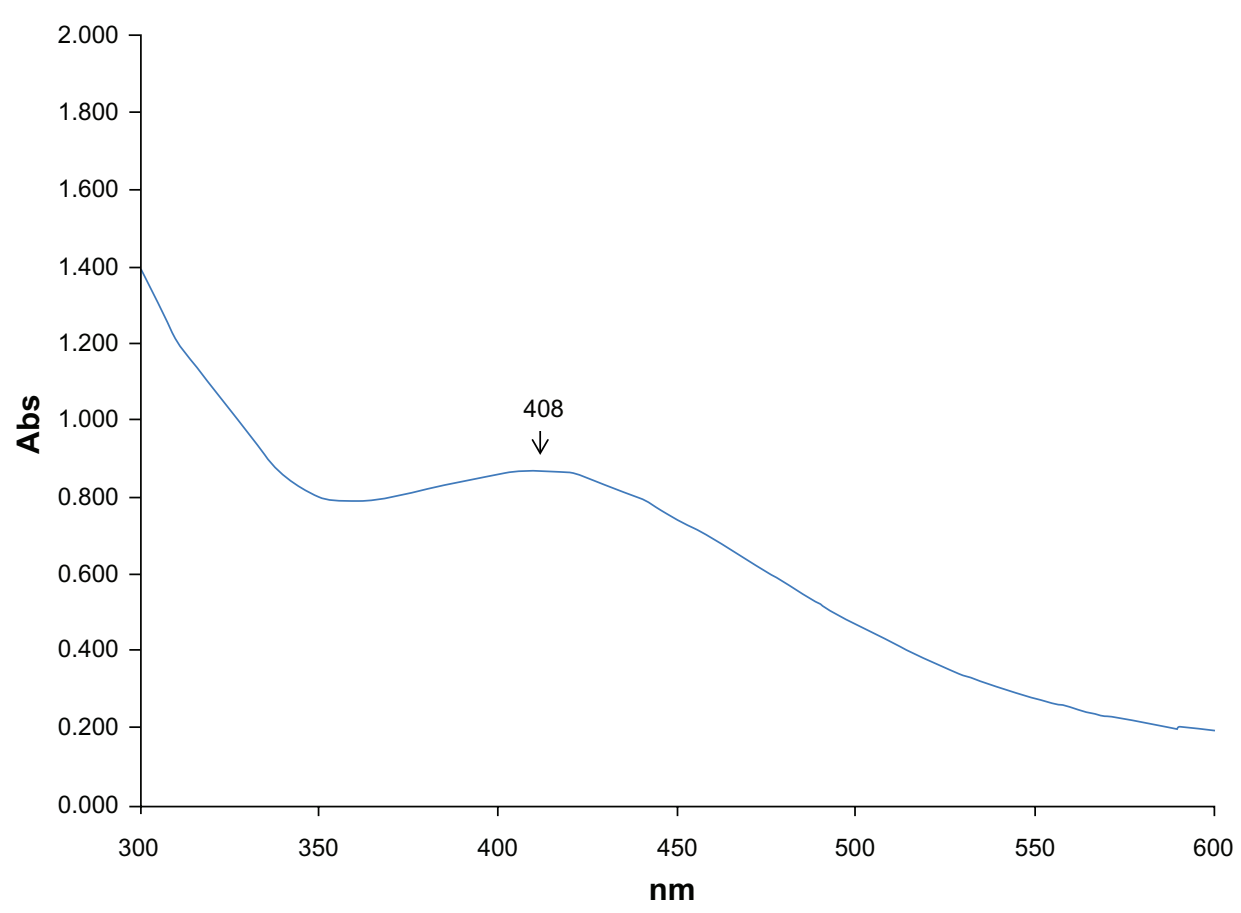

Figure 2 Ultraviolet-visible absorption spectrum of silver nanoparticles synthesized using aqueous extract of Parmotrema praesorediosum. 

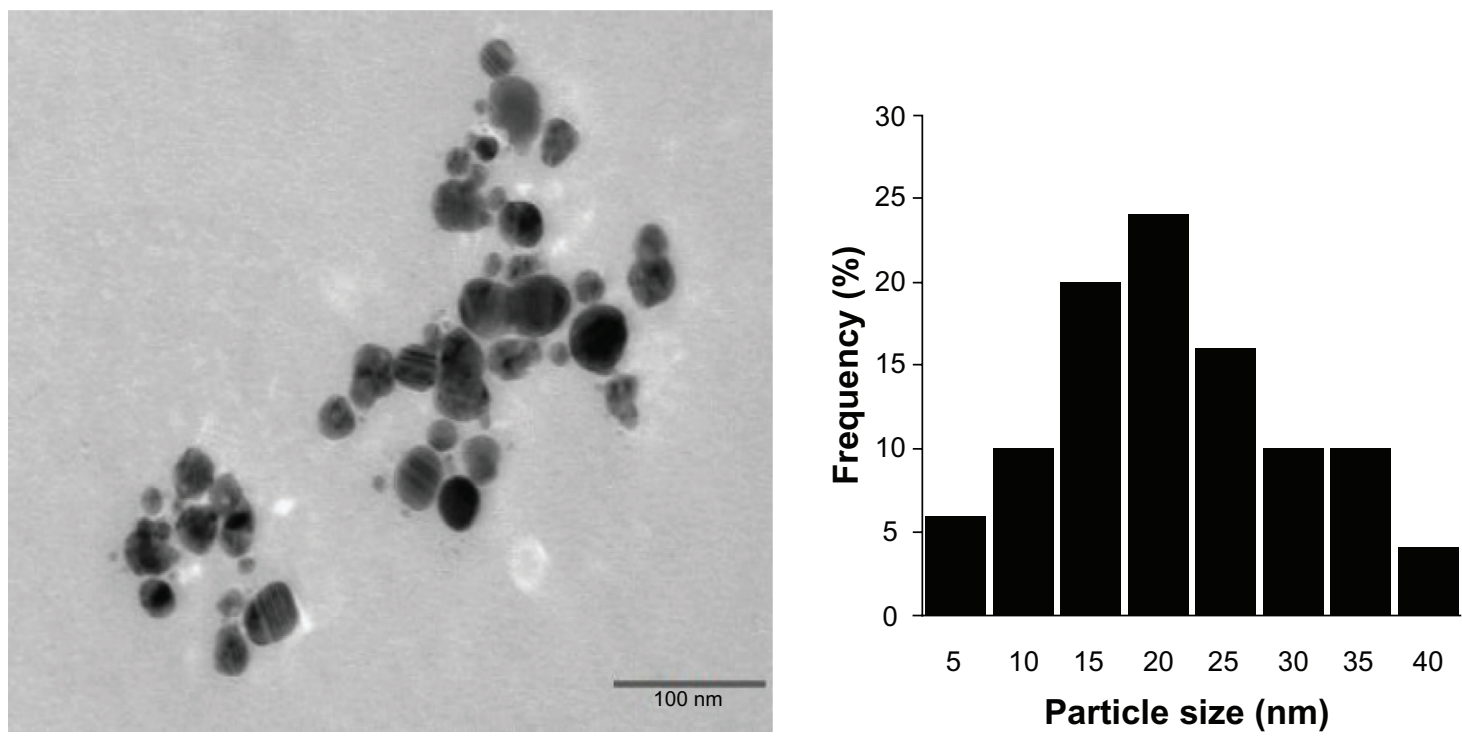

Figure 3 Transmission electron microscopic image of silver nanoparticles obtained using Parmotrema praesorediosum extract after 24 hours of reaction (left) and particle size distribution (right).

\section{Discussion}

The development of easy, reliable, and ecofriendly methods helps to increase interest in the synthesis and application of nanoparticles that are beneficial for mankind..$^{22,23}$ Recently, plant extracts and natural resources have been found to be useful in the reduction of silver ions to AgNPs. Silver nanoparticles show a dark reddish-brown color in aqueous solution due to the surface plasmon resonance phenomenon. ${ }^{24}$ The surface plasmon resonance band of AgNPs can be monitored through the ultraviolet-visible spectrum ranging from $400 \mathrm{~nm}$ to $450 \mathrm{~nm}$, indicating formation of AgNPs. ${ }^{25} \mathrm{Also}$, it is well recognized that the absorbance of AgNPs depends mainly upon size and shape. ${ }^{26}$ The technique outlined above has proven to be very useful for analysis of nanoparticles. ${ }^{27-29}$ According to Mock et al, the morphology of nanoparticles is highly variable, and includes spherical, rod-like, decahedral, triangular, and platelet shapes. This could be due to correlation of the absorption spectrum for individual AgNPs. ${ }^{30}$

The chemical composition and crystal structure of a material are often determined by X-ray diffraction analysis. The presence of AgNPs in plant extracts can be identified using X-ray diffractometry to examine the diffraction peaks

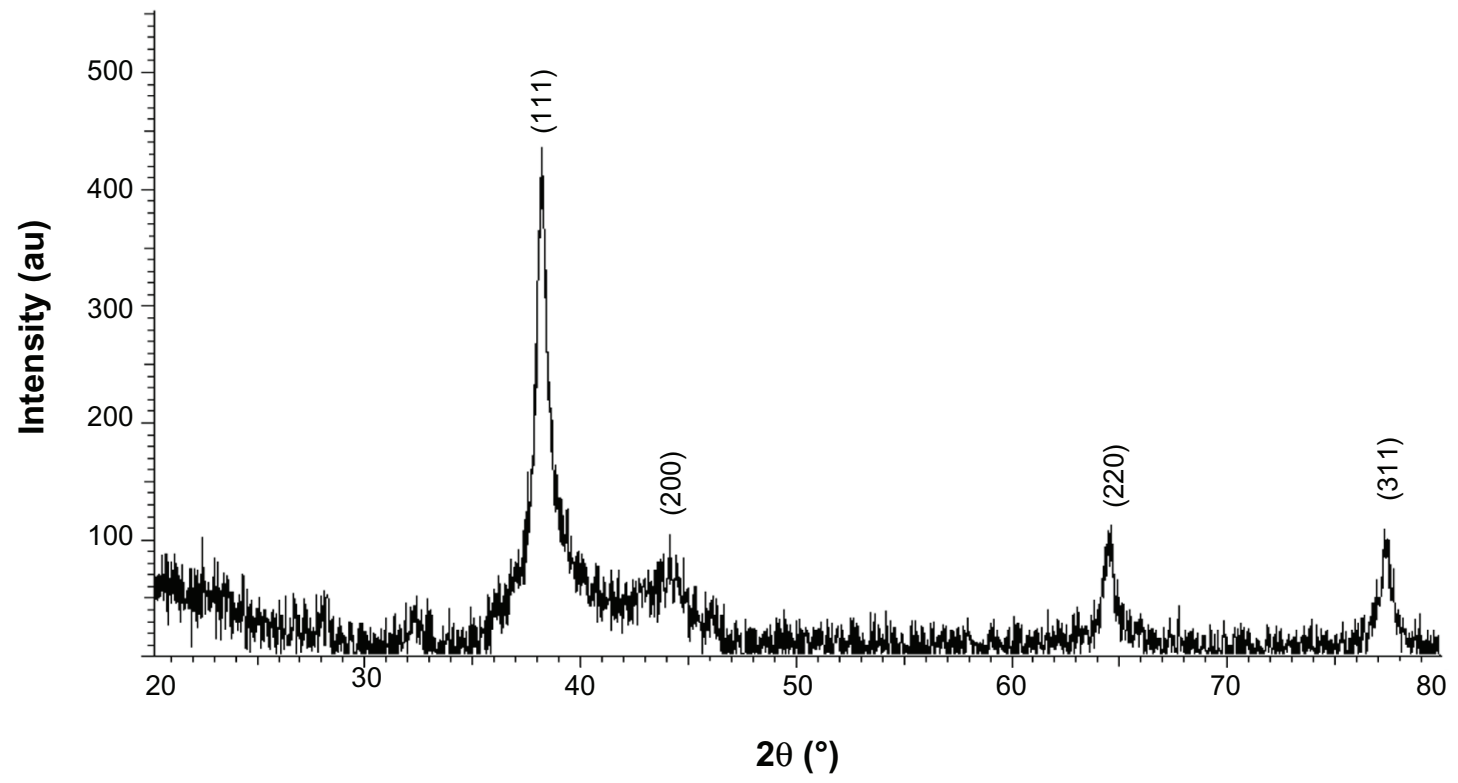

Figure 4 X-ray diffraction pattern of the prepared silver nanoparticles. 


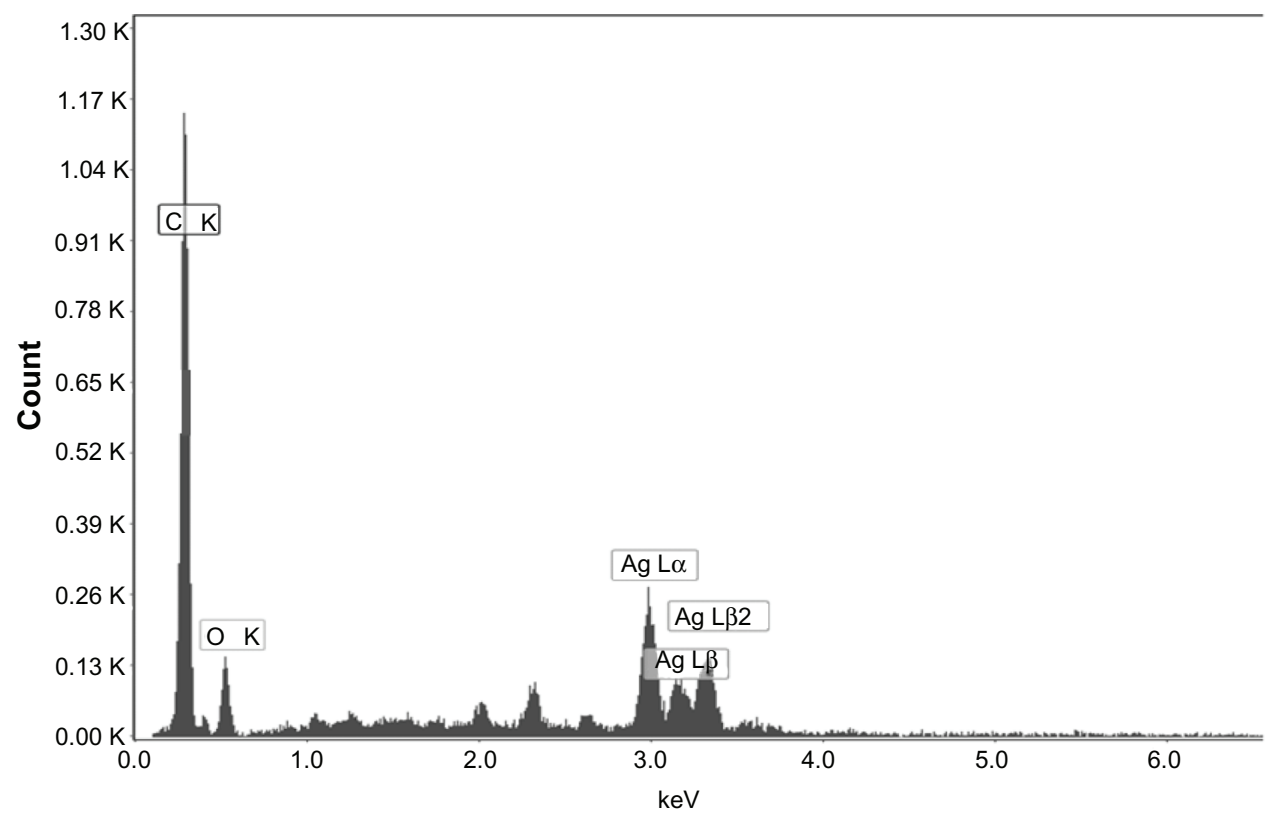

Figure 5 Energy-dispersive spectrum of silver nanoparticles synthesized by treating I $\mathrm{mM} \mathrm{AgNO}_{3}$ with an aqueous extract of Parmotrema praesorediosum Abbreviations: CK, carbon peak; OK, oxygen peak.

of the plant. ${ }^{31}$ In this work, we discovered that the synthesized AgNPs match the face-centered cubic crystal structure of metallic silver. This result is consistent with the results reported by Jain et al, ${ }^{1}$ Cruz et al, ${ }^{2}$ and Gilaki. ${ }^{3}$

Energy-dispersive spectroscopy is used to gain further insight into the features of AgNPs. Throughout the scanning range of binding energies, the peak around $3.40 \mathrm{keV}$ corresponds to the binding energies of AgL..$^{32}$ Some impurity peaks were detected below $1 \mathrm{keV}$, corresponds to a carbon peak (CK) and oxygen peak (OK), which was probably related to the presence of crystalline biomolecules in the extract. The $P$. praesorediosum extract contains several metabolites,

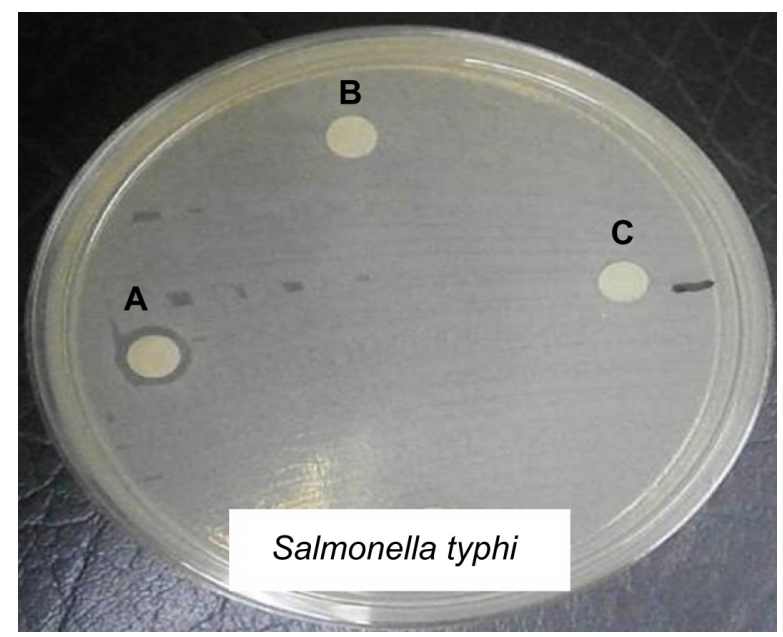

Figure 6 Antibacterial activity assay against Salmonella typhi by the disk diffusion method. (A) Synthesized silver nanoparticles, (B) distilled water, and (C) Parmotrema praesorediosum aqueous extract. including antranorin, (+)-praesorediosic acid, and (+)-protopraesorediosic acid, ${ }^{33}$ that may play a significant role as reducing agents for silver ions. Special consideration is needed to investigate the synergistic effects of AgNPs with biomolecules.

Silver has been used for many years for antimicrobial applications in the medical field. ${ }^{34,35}$ Recently, in the field of nanotechnology, applications of AgNPs as antimicrobial agents have been expanding. The exact mechanism by which silver ions and AgNPs exert their antibacterial effect remains to be identified. A literature survey shows that smaller AgNPs having a large surface area available for interaction would have a stronger antibacterial effect than larger AgNPs. ${ }^{36}$ It is also possible that AgNPs not only interact with the membrane surface, but may also penetrate inside bacteria. ${ }^{37}$

Table I Mean zone of inhibition $(\mathrm{mm})$ of silver nanoparticles synthesized by Parmotrema praesorediosum against eight pathogenic micro-organisms

\begin{tabular}{|c|c|c|}
\hline \multirow[t]{2}{*}{ Pathogens } & \multicolumn{2}{|c|}{ Zone of inhibition (mm) } \\
\hline & $\begin{array}{l}\text { I } 00 \mu \mathrm{g} / \mathrm{mL} \\
\text { aqueous extract }\end{array}$ & $\begin{array}{l}\text { I } 00 \mu \mathrm{g} / \mathrm{mL} \text { silver } \\
\text { nanoparticles }\end{array}$ \\
\hline Proteus vulgaris & 6 & $8 \pm 0.0$ \\
\hline Pseudomonas aeruginosa & 6 & $8 \pm 0.8$ \\
\hline Serratia marcescens & 6 & $8 \pm 0.3$ \\
\hline Salmonella typhi & 6 & $7.5 \pm 0.0$ \\
\hline Staphylococcus epidermidis & 6 & 6 \\
\hline Methicillin-resistant & 6 & 6 \\
\hline \multicolumn{3}{|l|}{ Staphylococcus aureus } \\
\hline Bacillus subtilis & 6 & 6 \\
\hline Streptococcus faecalis & 6 & 6 \\
\hline
\end{tabular}

Note: The disk diameter is $6 \mathrm{~mm}$. 
According to Kim et al, ${ }^{13}$ the antibacterial effects of AgNPs may be associated with the characteristics of certain bacterial species. In this investigation, we found that AgNPs synthesized using $P$. praesorediosum have potential antibacterial activity against Gram-negative bacteria, in a manner similar to that reported by Shrivastava and Dash. ${ }^{38}$

\section{Conclusion}

We have demonstrated a good method for developing a simple, safe, cost-effective, and ecofriendly preparation of AgNPs in an aqueous extract of $P$. praesorediosum. To the authors' knowledge, this is the first report concerning use of a lichen species to reduce silver ions to AgNPs. The synthesized AgNPs had an average particle size of $19 \mathrm{~nm}$ and a cubic structure, and remained stable without agglomeration for more than one month. They showed potential antibacterial activity against Gram-negative bacteria. Thus, application of these synthesized AgNPs based on our findings may lead to valuable discoveries in various fields, including medical devices and in the pharmaceutical and biomedical industries. Toxicity studies of these AgNPs using human pathogens may open the door to a new range of antibacterial agents.

\section{Acknowledgment}

The research was supported by the Exploratory Research Grant Scheme (ERGS/1/2012/STG01/UKM/01/3), the Ministry of Higher Education, Malaysia, the Universiti Kebangsaan Malaysia, Malaysia, and the Universiti Teknologi MARA, Malaysia.

\section{Disclosure}

The authors report no conflicts of interest in this work.

\section{References}

1. Jain D, Daima HK, Kachhwaha S, Kothari SL. Synthesis of plant-mediated silver nanoparticles using papaya fruit extract and evaluation of their antimicrobial activities. Dig J Nanomater Biostruct. 2009;4:557-563.

2. Cruz D, Fale PL, Mourato A, Vaz PD, Serralheiro ML, Lino ARL. Preparation and physicochemical characterization of Ag nanoparticles biosynthesized by Lippia citriodora (lemon verbena). Colloids Surf B Biointerfaces. 2010;81:67-73.

3. Gilaki M. Biosynthesis of silver nanoparticles using plant extracts. $J$ Biol Sci. 2010;10:465-467.

4. Vilchis-Nestor AR, Sánchez-Mendieta V, Camacho-Lopez MA, GómezEspinosa RM, Camacho-López ZR, Arenas JA. Solventless synthesis and optical properties of $\mathrm{Au}$ and $\mathrm{Ag}$ nanoparticles using Camellia sinensis extract. Mater Lett. 2008;62:3103-3105.

5. Chandran SP, Chaudhary M, Pasricha R, Ahmad A, Sastry M. Synthesis of gold nanotriangles and silver nanoparticles using Aloe vera plant extract. Biotechnol Prog. 2006;22:577-583.

6. Gurunathan S, Kalishwaralal K, Vaidyanathan R, Deepak V, Pandian SRK, Muniyandi J. Biosynthesis, purification and characterization of silver nanoparticles using Escherichia coli. Colloids Surf B Biointerfaces. 2009;74:328-335.
7. Parashar V, Parashar R, Sharma B, Pandey AC. Parthenium leaf extract mediated synthesis of silver nanoparticles: a novel approach towards weed utilization. Dig J Nanomater Biostruct. 2009;4:45-50.

8. Ip M, Lui SL, Poon VKM, Lung I, Burd A. Antimicrobial activities of silver dressings: an in vitro comparison. JMed Microbiol. 2006;55(Pt 1): $59-63$.

9. Kim K-J, Sung W, Suh B, et al. Antifungal activity and mode of action of silver nano-particles on Candida albicans. Biometals. 2009;22: 235-242.

10. Lara H, Ayala-Nunez N, Ixtepan-Turrent L, Rodriguez-Padilla C. Mode of antiviral action of silver nanoparticles against HIV-1. J Nanobiotechnology. 2010;8:1.

11. Shrivastava S, Bera T, Singh SK, Singh G, Ramachandrarao P, Dash D. Characterization of antiplatelet properties of silver nanoparticles. ACS Nano. 2009;3:1357-1364.

12. Rai M, Yadav A, Gade A. Silver nanoparticles as a new generation of antimicrobials. Biotechnol Adv. 2009;27:76-83.

13. Kim JS, Kuk E, Kim JH, et al. Antimicrobial effects of silver nanoparticles. Nanomed Nanotechnol Biol Med. 2007;3:95-101.

14. Samsudin MW. Liken: Tumbuhan Primitif Yang Masih Relevan. UKM Press: 2010.

15. Elix JA, Whitton, AA, Sargent MW. Recent Progress in the Chemistry of Lichen Substances. New York, NY: Springer-Verlag/Wein; 1984.

16. Culberson CF. Chemical and botanical guide to lichens products. Königstein, Germany: Otto Koeltz Science Publishers; 1979.

17. Clinical and Laboratory Standards Institute. M7-A7, Methods for Dilution Antimicrobial Susceptibility Tests for Bacteria That Grow Aerobically; Approved Standard. 7th ed. Wayne, PA: Clinical and Laboratory Standards Institute; 2006.

18. Ahmad A, Mukherjee P, Senapati S, Mandal D, Islam KM, Kumar R. Extracellular biosynthesis of silver nanoparticles using the fungus Fusarium oxysporum. Colloids Surf B Biointerfaces. 2003;28:313-318.

19. Shankar SS, Rai A, Ankamwar B, Singh A, Ahmad A, Sastry M. Biological synthesis of triangular gold nanoprisms. Nat Mater. 2004;3: 482-488.

20. Magudapathy P, Gangopadhyay P, Panigrahi BK, Nair KGM, Dhara S. Electrical transport studies of Ag nanocrystallites embedded in glass matrix. Physica B Condens Matter. 2001;299:142-146.

21. Silver S, Phung LT. Bacterial heavy metal: new surprises. Annu Rev Microbiol. 1996;50:753-789.

22. Bhattacharya D, Gupta RK. Nanotechnology and potential of microorganisms. Crit Rev Biotechnol. 2005;25:199-204.

23. Vankar PS, Bajpai D. Preparation of gold nanoparticles from Mirabilis jalapa flowers. Indian J Biochem Biophys. 2010;47:157-160.

24. Krishnaraj C, Jagan EG, Rajasekar S, Selvakumar P, Kalaichelvan PT, Mohan N. Synthesis of silver nanoparticles using Acalypha indica leaf extracts and its antibacterial activity against water borne pathogens. Colloids Surf B Biointerfaces. 2010;76:50-56.

25. Mulvaney P. Surface plasmon spectroscopy of nanosized metal particles. Langmuir. 1996;12:788-800.

26. Kerker M. The optics of colloidal silver: something old and something new. J Colloid Interface Sci. 1985;105:297-314.

27. Henglein A. Physicochemical properties of small metal particles in solution: microelectrode reactions, chemisorption, composite metal particles, and the atom-to-metal transition. J Phys Chem. 1993;97:5457-5471.

28. Sastry M, Mayya KS, Bandyopadhyay K. pH-dependent changes in the optical properties of carboxylic acid derivatized silver colloidal particles. Colloids Surf A Physicochem Eng Asp. 1997;127:221-228.

29. Sastry M, Patil V, Sainkar SR. Electrostatically controlled diffusion of carboxylic acid derivatized silver colloidal particles in thermally evaporated fatty amine films. J Phys Chem B. 1998;102:1404-1410.

30. Mock JJ, Barbic M, Smith DR, Schultz DA, Schultz S. Shape effects in plasmon resonance of individual colloidal silver nanoparticles. JChem Phys. 2002;116:6755-6760.

31. Panneerselvam C, Ponarulselvam S, Murugan K, Kalimuthu K, Thangamani S. Synthesis of silver nanoparticles using leaves of Catharanthus roseus Linn. G. Don and their antiplasmodial activities. Asian Pac J Trop Biomed. 2012;2:574-580. 
32. Forough M, Farhadi K. Biological and green synthesis of silver nanoparticles. Turkish J Eng Env Sci. 2010;34:281-287.

33. Davied F, Elix JA, Samsudin MW. Two new aliphatic acids from lichen Parmotrema prasorediosum. Aust J Chem. 1990;43:1297-1300.

34. Alt V, Bechert T, Steinrücke P, et al. An in vitro assessment of the antibacterial properties and cytotoxicity of nanoparticulate silver bone cement. Biomaterials. 2004;25:4383-4391.

35. Russell AD, Hugo WB. Antimicrobial activity and action of silver. Prog Med Chem. 1994;31:351-370.
36. Kvitek L, Panacek A, Soukupova J, et al. Effect of surfactants and polymers on stability and antibacterial activity of silver nanoparticles (NPs). J Phys Chem C. 2008;112: $5825-5834$.

37. Morones JR, Elechiguerra JL, Camacho A, et al. The bactericidal effect of silver nanoparticles. Nanotechnology. 2005;16:2346-2353.

38. Shrivastava S, Dash D. Agrifood nanotechnology: living revolution in food and agriculture. J Nanotechnology. 2009;12:240-243.
International Journal of Nanomedicine

\section{Publish your work in this journal}

The International Journal of Nanomedicine is an international, peerreviewed journal focusing on the application of nanotechnology in diagnostics, therapeutics, and drug delivery systems throughout the biomedical field. This journal is indexed on PubMed Central, MedLine, CAS, SciSearch ${ }^{\circledR}$, Current Contents ${ }^{\circledR} /$ Clinical Medicine,

\section{Dovepress}

Journal Citation Reports/Science Edition, EMBase, Scopus and the Elsevier Bibliographic databases. The manuscript management system is completely online and includes a very quick and fair peer-review system, which is all easy to use. Visit http://www.dovepress.com/ testimonials.php to read real quotes from published authors.

Submit your manuscript here: http://www.dovepress.com/international-journal-of-nanomedicine-journal 